Article

\title{
Development and Evaluation of a Novel Taqman Real-Time PCR Assay for Rapid Detection of Mycoplasma bovis: Comparison of Assay Performance with a Conventional PCR Assay and Another Taqman Real-Time PCR Assay *
}

\section{Hemant Naikare ${ }^{\dagger} * *$, Daniela Bruno ${ }^{\dagger}$, Debabrata Mahapatra, Alesia Reinisch, Russell Raleigh and Robert Sprowls}

Texas A\&M Veterinary Medical Diagnostic Laboratory, 6610 Amarillo Blvd West, Amarillo, TX 79106, USA; E-Mails: danirbruno@gmail.com (D.B.); debabrata77@gmail.com (D.M.); areinisch@tvmdl.tamu.edu (A.R.); r-raleigh@tvmdl.tamu.edu (R.R); r-sprowls@tvmdl.tamu.edu (R.S.)

$\dagger$ These authors contributed equally to this work.

* Some of the data included in this manuscript was presented at the 55th American Association of Veterinary Laboratory Diagnosticians (AAVLD) Annual Meeting, Greensboro, NC, USA, 18-24 October 2012.

* Author to whom correspondence should be addressed; E-Mail: hnaikare@tvmdl.tamu.edu; Tel.: +1-806-353-7478; Fax: +1-806-359-0636.

Academic Editors: Duncan C. Ferguson and Margarethe Hoenig

Received: 27 December 2014 / Accepted: 6 March 2015 / Published: 16 March 2015

\begin{abstract}
The objective of this study was to develop and validate a Taqman real-time PCR assay for the detection of Mycoplasma bovis (M. bovis). Unique primers targeting the highly conserved house-keeping gene $(u v r C)$ were designed and the probe sequence was derived from a previously published microarray study. There was $100 \%$ agreement in the outcome between our assay and the other two published assays for M. bovis detection. The analytical limit of detection of our assay is 83 copies of the $u v r C$ gene. This assay was validated on atal of 214 bovine clinical specimens that were submitted to the Texas A\&M Veterinary Medical Diagnostic Laboratory (TVMDL), Texas, USA. The specificity of the assay was assessed to be $100 \%$ since no cross-reactivity occurred with 22 other bacterial and other Mycoplasma species. We conclude that the $u v r C$ gene serves as a good and reliable diagnostic marker for the accurate and rapid detection of $M$. bovis from a wider variety of specimen matrices.
\end{abstract}


Keywords: Mycoplasma bovis; cattle; Taqman real-time PCR; uvrC gene

\section{Introduction}

Mycoplasma bovis (M. bovis) continues to be a significant economic burden to the beef and dairy cattle industries. It is a major bovine mycoplasma pathogen associated with pneumonia, mastitis, arthritis, and abortion. It has been reported that $M$. bovis accounts for monetary losses of about 150 million euros across Europe and more than \$100 million/year in the US due to mastitis and respiratory disease [1].

M. bovis, which belongs to the family Mycoplasmataceae in the class Mollicutes, is characterized by its small genome size (580-1380 kb), devoid of cell wall, and require complex growth media [2]. M. bovis is widespread within the bovine population in enzootically infected areas. Infection is usually introduced into $M$. bovis-free herds by asymptomatic calves or adult carrier cattle that are actively shedding the organism. Organisms can be shed via the respiratory tract for many months or even years, and such animals act as a reservoir of infection. Contact animals become infected via the respiratory tract, the teat canal, genital tract or artificial insemination with infected semen [1].

Infections caused by M. bovis are difficult to treat by antibiotic therapy. Their lack of cell wall makes them resistant to antimicrobials that target the cell wall such as beta-lactams [1,3]. Control methods rely mainly on culling infected animals and testing newly purchased animals before addition to the herd and maintaining extensive hygiene within the premises [4]. Hence, rapid and reliable diagnostic tools are in constant demand to detect infected animals and control the disease caused by M. bovis.

In comparison to the other bacterial pathogens that affect cattle, M. bovis are slow growers, and their fastidious growth requires the addition of sterols. It may take 3 to 10 days to grow at $37{ }^{\circ} \mathrm{C}$ in presence of $5 \%-10 \% \mathrm{CO}_{2}$. They produce "centered" colonies that give a "fried-egg" like appearance [5]. Although scientific literature cites culture as the gold standard method for detection of $M$. bovis, culture offers limited sensitivity and specificity due to multiple factors $[1,6,7]$. Serological tests determine previous exposure to $M$. bovis and are considered to be more sensitive than culture in diagnosing chronic infections. Different types of ELISA tests with whole cell or treated antigen have been described to detect antibodies in milk and serum and are also commercially available. Antibodies to M. bovis can be detected with various immunological methods including counter current electrophoresis, ELISA, immunoblotting, immunobinding and immunohistochemistry methods [8]. Although serology can help in identifying mycoplasma negative herds, the presence of high sero-prevalance in many populations limits the utility of serological tests [7].

The complete genome sequence of the international reference strain of M. bovis PG45 (ATCC 25523) has been reported [9]. Several PCR based molecular tests have been published which allow M. bovis identification using conventional, SYBR, Taqman real-time PCR or loop-mediated isothermal amplification (LAMP) platforms with varying sensitivity and specificity indices [10-15]. The known diagnostic targets for $M$. bovis detection primarily include $16 \mathrm{~S} r R N A$ and $u v r C$ genes. The $u v r C$ gene is a highly conserved housekeeping gene that encodes for a DNA repair enzyme "deoxyribodipyrimidine photolyase" [10]. Subramaniam and colleagues have demonstrated that although the $u v r C$ gene is well conserved in M. bovis and in another small ruminant pathogen Mycoplasma agalactiae, this gene differs significantly between the two phylogenetically closely related Mycoplasma species [10]. Thomas and 
colleagues [16] have demonstrated the $u v r C$ gene to be a conserved target suitable for PCR based diagnostics by PCR amplification and sequencing from ninety-two and twenty $M$. bovis strains respectively. Interestingly, Marenda and colleagues [17] have demonstrated the limitation of $u v r C$ target's universality for $M$. bovis detection since the $u v r C$ gene sequences are only slightly divergent making it difficult to differentiate $M$. bovis and M. agalactiae. Based on their suppression subtractive hybridization study, Marenda and colleagues have further proposed that the polC target based PCR should be included as a complement to the $u v r C$ target based detection of $M$. bovis [17]. Other diagnostic markers that have been reported for PCR based identification of $M$. bovis include an ATP binding protein oppD/F and membrane protein 81 [7].

Our objective was to develop and evaluate a rapid and accurate $u v r C$ gene-based Taqman real-time PCR assay for the detection of $M$. bovis in a wide variety of clinical specimen matrices that can be utilized for routine diagnostic testing, molecular surveillance, and export testing.

\section{Experimental Section}

\subsection{Clinical Specimens}

A total of 214 specimens comprising milk samples: individual animals and bulk tanks (78); fresh lungs (45); joint fluids (5); semen (8); and nasal swabs (78) submitted to the TVMDL laboratory for culture and/or M. bovis PCR were included in this study. These specimens originated from dairy farms, beef feed lots, and from bison farms across Texas and other states in the US.

\subsection{DNA Extraction}

The clinical specimens were prepared for nucleic acid purification as follows: (i) milk: $\sim 25$ to $50 \mathrm{~mL}$ of milk sample was pelleted by centrifuging at 3000-4000 g for 15-20 min. The supernatant fat and excess liquid were removed, and the pellet was washed twice with sterile phosphate buffered saline (PBS). The washed pellet was re-suspended in $200 \mu \mathrm{L}$ of sterile PBS and then used for nucleic acid purification; (ii) Lung tissues: $\sim 1-2$ grams of tissue was aliquoted and mixed with 10-20 mL of sterile PBS and homogenized using a stomacher $(10 \% \mathrm{w} / \mathrm{v})$ (Stomacher ${ }^{\circledR}$ Lab Blender Model 8.0 Seward Medical Limited, London-UK 10/94). Following disruption, $200 \mu \mathrm{L}$ of the tissue supernatant was used for nucleic acid purification; (iii) Nasal swab samples were directly re-suspended in $\sim 400$ to $500 \mu \mathrm{L}$ of sterile PBS and $200 \mu \mathrm{L}$ of it was used for nucleic acid extraction; (iv) semen and joint fluid specimens: $200 \mu \mathrm{L}$ of specimen was directly used for nucleic acid extraction; (v) Mycoplasma sp. isolates/colonies: $\sim 1-4$ colonies were transferred into $200 \mu \mathrm{L}$ of sterile PBS using sterile disposable loop, and subjected to nucleic acid purification.

The nucleic acid purification from $200 \mu \mathrm{L}$ of processed clinical specimens was performed using QIAamp DNA mini kit (Qiagen \#51306) as per the manufacturer's instructions. DNA was eluted in $100 \mu \mathrm{L}$ of sterile water and stored at $-20^{\circ} \mathrm{C}$ until the PCR amplification could be performed.

\subsection{TaqMan Real-Time PCR Assay}

The M. bovis uvrC gene sequence was retrieved from the Genbank accession \# AF003959.1. M. bovis species specific primers were designed using Primer3 software (http://frodo.wi.mit.edu/). The probe 
sequence was derived from a previously published microarray study [18]. The primers and probe were synthesized from IDT-DNA and Life Technologies respectively, and the sequence information is listed in Table 1.

Table 1. Sequences of primers and probes used in this study.

\begin{tabular}{|c|c|c|c|c|}
\hline Gene Target & Oligo & Sequence $\left(5^{\prime} \rightarrow 3^{\prime}\right)$ & Reference & Product Size \\
\hline \multirow{3}{*}{$u v r C$} & Forward Primer & GAG AAT GCT TCA GTA TTT TGA CGG & This study & \multirow{3}{*}{$170 \mathrm{bp}$} \\
\hline & Reverse Primer & CAA AAG CAA AAT GTT AAA TTC AGG & This study & \\
\hline & Probe & (6 FAM) CAT ATA TAA GTG AGA CTA ACT TAT T(MGB) & [18] & \\
\hline \multirow{3}{*}{$u v r C$} & F2024 & TCT AAT TTT TTC ATC ATC GCT AAT GC & \multirow{3}{*}{ [12] } & \multirow{3}{*}{$112 \mathrm{bp}$} \\
\hline & $\mathrm{R} 2135$ & TCA GGC CTT TGC TAC AAT GAA C & & \\
\hline & M.bov & (FAM) AAC TGC ATC ATA TCA CAT ACT (MGB) & & \\
\hline \multirow{2}{*}{ 16S rRNA } & Forward Primer & CCT TTT AGA TTG GGA TAG CGG ATG & \multirow{2}{*}[19]{} & \multirow{2}{*}{$360 \mathrm{bp}$} \\
\hline & Reverse Primer & CCG TCA AGG TAG CAT CAT TTC CTA T & & \\
\hline
\end{tabular}

Taqman real-time PCR was carried out in Applied Biosystems 7300 or 7500 Fast thermal cycler instruments (Applied Biosystems, Foster City, CA, USA) in a standard mode. The PCR was performed in a $20 \mu \mathrm{L}$ final reaction volume. The $3 \mu \mathrm{L}$ of template DNA was added to $17 \mu \mathrm{L}$ master mix prepared with TaqPCR core kit (Qiagen \#201225) containing $2.0 \mu \mathrm{L} 10 \mathrm{X}$ PCR buffer, $0.4 \mu \mathrm{L}$ dNTP (10 mM each), $2.4 \mu \mathrm{L} \cdot \mathrm{MgCl}_{2}(25 \mathrm{mM}), 0.8 \mu \mathrm{L}$ each of forward and reverse primers $(25 \mu \mathrm{M}), 0.8 \mu \mathrm{L}$ of probe $(7.5 \mu \mathrm{M}), 0.25 \mu \mathrm{L}$ Taq DNA Polymerase (5 units $/ \mu \mathrm{L})$ and $9.55 \mu \mathrm{L}$ of water. The PCR assay was performed using 96-well plates that were sealed with optical sealing tape (Applied Biosystems, Foster City, CA, USA). Reaction mixtures containing water substituted for DNA templates were used as negative controls. The thermocycling conditions were set as per the following parameters: $95{ }^{\circ} \mathrm{C}$ for $8 \mathrm{~min}, 40$ cycles of $95^{\circ} \mathrm{C}$ for $20 \mathrm{~s}$, and $60{ }^{\circ} \mathrm{C}$ for $1 \mathrm{~min}$. Fluorescence was read at the end of each round of the annealing step. Specimens that produced an increase in the fluorescence signal of the reporter dye over the threshold value (set at $10 \%$ of the maximum fluorescence of the positive amplification control), auto baseline, and produced a characteristic sigmoidal curve were considered to be positive for M. bovis. The DNA extracts from all the specimens were also tested for M. bovis by conventional PCR, and its sensitivity and specificity was compared to our Taqman assay. Conventional PCR was carried out in a T3 Thermocycler (Biometra- Göttingen, Germany), and the conditions used were as described by Gonzalez et al. [19]. Similarly, our Taqman assay was compared to the Taqman assay of Clothier et al. using their recipe and thermocycling conditions [12]. Table 1 provides sequence information of primers and probe used for conventional PCR as per Gonzalez et.al. [19] and Taqman PCR as per Clothier et.al. [12].

\subsection{Culture}

Culture was carried out directly from the clinical specimens in accordance with the protocol described previously by Goll and colleagues [2]. The specimens were processed as follows: (i) lung tissues: an incision was made on the tissue surface with a sterile scalpel blade. A sterile cotton tipped applicator was penetrated into the incised tissue to obtain the inoculum, which was then cultured on Hayflick's mycoplasma agar plates; (ii) milk samples, joint fluids, and semen samples: a sterile cotton tipped applicator was dipped into the clinical specimen, and the inoculum was cultured on Hayflick's mycoplasma agar 
plates; (iii) nasal swabs: they were directly plated onto Hayflick's mycoplasma agar plates. The inoculated plates were incubated at $37{ }^{\circ} \mathrm{C}$ with $5 \% \mathrm{CO}_{2}$ for one week and were examined under a dissecting microscope for mycoplasma growth every other day during the incubation. The characteristic "fried egg" like "centered" colony appearance was interpreted as positive culture for M. bovis [2].

\subsection{Sensitivity and Specificity Analyses}

The specificity of the M. bovis Taqman assay was assessed using genomic DNA from 22 different bacterial and Mycoplasma species that could potentially be encountered with mastitis, arthritis and pulmonary infections in ruminants (Table 2). A subset of clinical specimens $(n=71)$ were also subjected to culture-based detection of $M$. bovis. The limit of detection and analytical sensitivity of the real-time assay was determined using 10-fold serial dilutions of a culture of M. bovis strain ATCC 25523 in triplicate. The number of copies of $M$. bovis template DNA was calculated using the online resource "dsDNA copy number calculator" from URI Genomics and sequencing center (http://www.uri.edu/research/gsc/resources/cndna.html).

Table 2. Mycoplasma sp. and other bacterial species tested for specificity of the real-time PCR assay.

\begin{tabular}{cclc}
\hline Number & Species & Strain & Real-Time PCR \\
\hline 1 & Mycoplasma bovis & ATCC 25523 & Positive \\
2 & Mycoplasma bovis & ATCC 27369 & Positive \\
3 & Mycoplasma bovis & Field isolate & Positive \\
4 & Mycoplasma alkalescens & ATCC 29103 & Negative \\
5 & Mycoplasma canadense & ATCC 29418 & Negative \\
6 & Mycoplasma arginini & ATCC 23838 & Negative \\
7 & Mycoplasma bovigenitalium & ATCC 27748 & Negative \\
8 & Staphylococcus aureus & Field isolate & Negative \\
9 & Streptococcus agalactiae & Field isolate & Negative \\
10 & Escherichia coli & Field isolate & Negative \\
11 & Corynebacterium pseudotuberculosis & Field isolate & Negative \\
12 & Streptococcus uberis & Field isolate & Negative \\
13 & Coagulase Negative Staphylococcus & Field isolate & Negative \\
14 & Pseudomonas aeruginosa & Field isolate & Negative \\
15 & Klebsiella pneumonia & Field isolate & Negative \\
16 & Proteus mirabilis & Field isolate & Negative \\
17 & Serratia marcescens & Field isolate & Negative \\
18 & Entereococcus faecalis & Field isolate & Negative \\
19 & Arcanobacterium pyogenes & Field isolate & Negative \\
20 & Candida spp & Field isolate & Negative \\
21 & Histophilus somnus & Field isolate & Negative \\
22 & Salmonella spp & Field isolate & Negative \\
23 & Bacillus cereus & Field isolate & Negative \\
24 & Pasteurella multocida & Field isolate & Negative \\
25 & Mannheimia haemolytica & Field isolate & Negative \\
\hline
\end{tabular}




\section{Results and Discussion}

\subsection{Limit of Detection}

Using 10-fold serial dilutions of genomic DNA extracted from pure culture of the international reference strain of $M$. bovis ATCC 25523 isolate, we determined the limit of detection for the $u v r C$ gene-based Taqman assay similar to the method employed for Bacillus anthracis PCR by Moser et al. [20]. The extracted DNA was quantified and checked for purity using NanoDrop ${ }^{\circledR}$ ND-1000 Spectrophotometer (Nanodrop Technologies, Inc. Wilmington, DE, USA). The DNA was tested in triplicate to determine the lowest detectable concentration, and the results indicated that the Taqman assay was able to detect 900 femtograms of total extracted DNA from all replicates (Figure 1). The genome length of M. bovis ATCC 25,523 was recently reported to be 1,003,404 bp [9]. Based on the observed $\mathrm{Ct}$ values and the standard curve, the assay demonstrated high sensitivity and was estimated to have a detection limit of $\sim 83$ copies of $u v r C$ gene (Figure 1) and approximately $4 \times 10^{2} \mathrm{cfu} / \mathrm{mL}$. The limit of detection of our Taqman assay is comparable to the limit of detection reported by Clothier et al. [12].

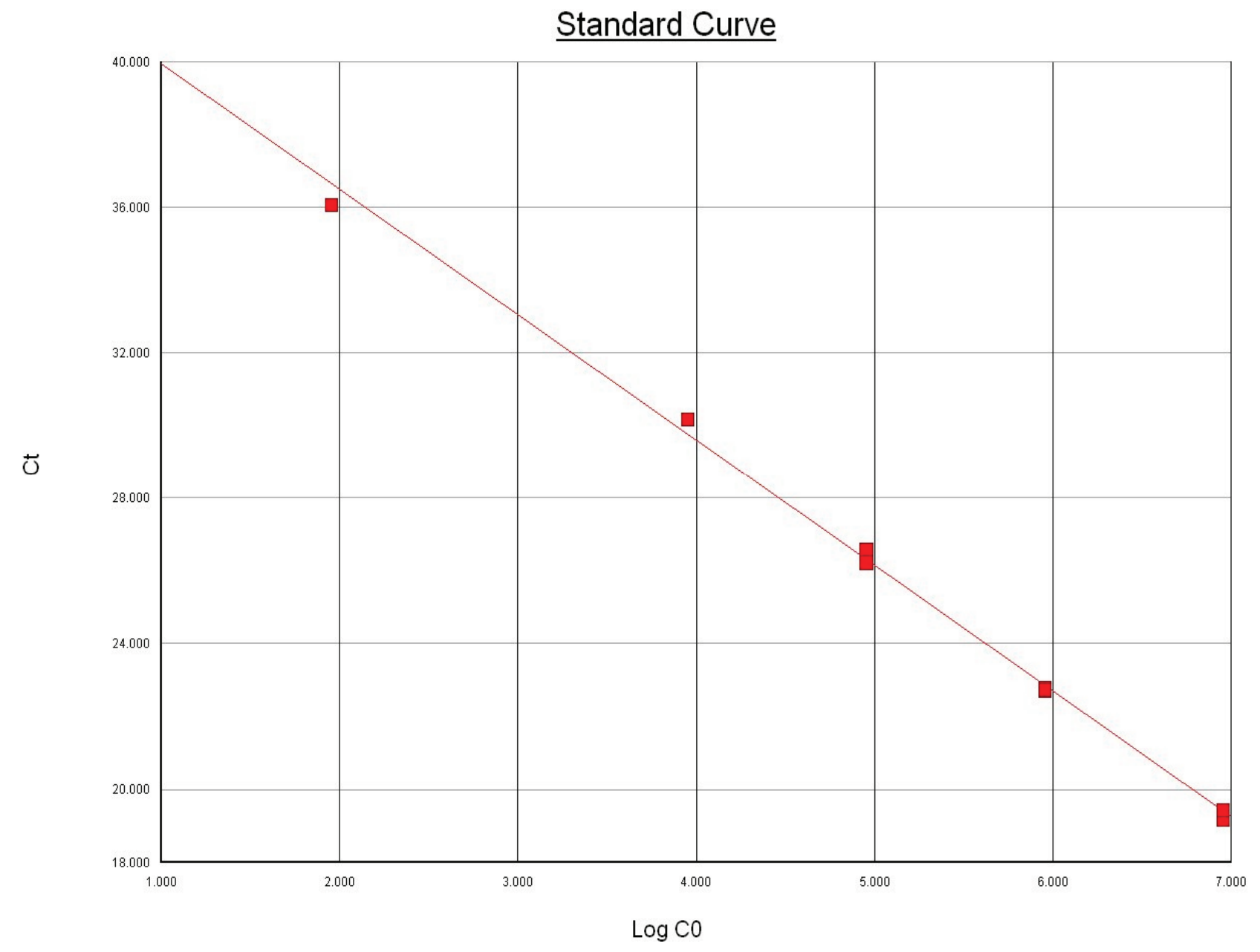

Figure 1. Relationship between the amount of template DNA copies (Log CO) in the Taqman assay and the mean threshold cycle $(\mathrm{Ct})$. Slope: -3.448840 ; intercept: 43.393936; $\mathrm{R}^{2}=0.996695$. 


\subsection{Assay Specificity}

The specificity of our Taqman assay was evaluated with genomic DNA from 22 bacterial and Mycoplasma species which could likely be present in infections from where M. bovis could be detected (Table 2). Both M. bovis ATCC isolates and a known clinical isolate of $M$. bovis were detected by the Taqman assay. No cross-reactivity was observed with other DNA targets, suggesting $100 \%$ specificity of the Taqman assay. The $u v r C$ gene in $M$. bovis has been shown to be stable and resistant to normal mutation process reinforcing its efficacy as a target for PCR assays [16]. Thomas et al. [16] have demonstrated the $u v r C$ gene to be a conserved target suitable for PCR based diagnostics by PCR amplification and sequencing from 92 and $20 \mathrm{M}$. bovis strains respectively. The specificity of our Taqman assay is similar to the specificity reported for another Taqman assay with $u v r C$ target for M. bovis detection [12].

\subsection{Assay Performance with Clinical Specimens}

Analysis of the specimens from our study revealed M. bovis by Taqman PCR in 82 out of the 214 specimens (Table 3). Out of these 82 positives, the break-up was as follows: $93.3 \%$ of lung samples were positive ( 42 of 45 ), 19.2\% of milk samples were positive (15 out of 78 ), $28.2 \%$ of nasal swabs were positive (22 of 78), $40 \%$ of joint fluid samples were positive ( 2 of 5 ), and $12.5 \%$ of semen specimens were positive ( 1 of 8$)$. Although transmission of $M$. bovis through infected semen has been cited as a route of infection [1], to our knowledge, this is the first report of a PCR confirmed positive for M. bovis from semen.

The performance of our Taqman assay matched 100\% (Table 3) with two previously published PCR methods: conventional PCR targeting the 16S rRNA [19] and Taqman real-time PCR targeting uvrC gene [12]. This study demonstrates our Taqman assay to have at least equivalent sensitivity and specificity as the other two PCR assays and that either of the two $u v r C$ targeting Taqman assays could be utilized for the rapid and accurate detection of M. bovis.

Table 3. Comparison between our Taqman PCR assay, conventional PCR and Clothier et al. Taqman assay.

\begin{tabular}{ccccccc}
\hline \multirow{2}{*}{ Specimen } & \multicolumn{2}{c}{ Our Taqman PCR Assay } & \multicolumn{2}{c}{ Conventional PCR } & \multicolumn{2}{c}{ Clothier et al. Taqman PCR Assay } \\
\cline { 2 - 7 } & Positive & Negative & Positive & Negative & Positive & Negative \\
\hline Lung $(n=45)$ & 42 & 3 & 42 & 3 & 42 & 3 \\
Milk $(n=78)$ & 15 & 63 & 15 & 63 & 15 & 63 \\
Nasal swab $(n=78)$ & 22 & 56 & 22 & 56 & 3 & 56 \\
Joint fluid $(n=5)$ & 2 & 3 & 2 & 7 & 1 & 3 \\
Semen $(n=8)$ & 1 & 7 & 1 & 132 & 82 & 7 \\
Total $(n=214)$ & 82 & 132 & 82 & 2 & 132 \\
\hline
\end{tabular}

$n=$ number of specimen of each kind of specimen matrix tested.

\subsection{Performance Comparison of Culture and Taqman PCR Assay}

Gonzalez et al. has demonstrated that pre-enrichment does not significantly increase the isolation of Mycoplasma sp. but increases the cost of diagnosis based on their comparative study of over 4000 milk 
samples which were tested for Mycoplasma sp. by both: direct inoculation of milk on Hayflick agar plates and pre-enrichment in Hayflick broth before culturing on Hayflick agar plates [21]. Therefore, we directly cultured the clinical specimens without pre-enrichment in the Hayflick mycoplasma broth.

Out of the 214 clinical specimens, a subset $(n=71)$ was evaluated for the presence of $M$. bovis by culture examination which is cited in the literature as the gold standard test for M. bovis detection (Table 4). Interestingly, only $35.21 \%(n=25)$ of these 71 specimens were positive for $M$. bovis by culture method, whereas $70.42 \%(n=50)$ were positive by our Taqman assay. Notably 27 out of the remaining 46 culture-negative specimens were positive by Taqman assay, while two specimens were positive by culture but negative by Taqman assay. Bell et al. recently reported similar findings and found PCR to detect $45.28 \%$ more of the positive $M$. bovis cases which were negative by the $M$. bovis culture test [22]. It is noteworthy that in addition to $M$. bovis, other bacterial and viral respiratory pathogens were also detected in some of the clinical specimens. However, in this study we did not investigate the concomitant M. bovis infections in presence or absence of these respiratory pathogens. The detection of M. bovis in clinical specimens may not always correlate with presence of an infectious underlying disease as $M$. bovis has been detected from both, clinically healthy animals and sick animals [23].

Table 4. Comparison between culture and our Taqman PCR assay.

\begin{tabular}{ccccc}
\hline \multirow{2}{*}{ Specimen } & \multicolumn{2}{c}{ Culture } & \multicolumn{2}{c}{ Our Taqman PCR Assay } \\
\cline { 2 - 5 } & Positive & Negative & Positive & Negative \\
\hline Lung $(n=40)$ & 17 & 23 & 39 & 1 \\
$\operatorname{Milk}(n=18)$ & 4 & 14 & 4 & 14 \\
Swabs $(n=10)$ & 4 & 6 & 6 & 4 \\
Joint Fluid $(n=3)$ & 0 & 3 & 1 & 2 \\
Total $(n=71)$ & 25 & 46 & 50 & 21 \\
\hline
\end{tabular}

Discrepancy between the outcome of culture results and Taqman assay results can be attributed to various factors. Due to the fastidious nature and fragility of Mycoplasma sp., suspected clinical specimens need to be promptly received within $24 \mathrm{~h}$ of sample collection in chilled condition to prevent loss of viability [7]. Whereas, PCR can detect M. bovis DNA from non-viable organisms and provides enhanced sensitivity compared to culture based examination [24]. Interestingly, Castillo-Alcala and colleagues have observed a large number of samples to be culture-positive for $M$. bovis, but were negative for M. bovis by hybridization probes based real-time PCR assay on a LightCycler platform [23]. Sensitivity of the PCR assays for M. bovis detection thus varies amongst different platforms of PCR. Isolation of $M$. bovis is significantly impaired from antibiotic treated animals and especially from lungs of chronically affected animals. Also co-infection, bacterial overgrowth, and contamination with other bacteria hinders with M. bovis isolation. Culture allows growth of all kinds of Mycoplasma species, and it is not specific for M. bovis detection as is the case with Taqman assay. Species level identification of M. bovis is not solely possible based on culture morphology, but requires further testing for confirmation by ELISA, PCR or immuno-histochemistry [7]. Inclusion of an internal extraction/ amplification control is recommended as it will assist in identifying any false negative results. As the internal control coamplifies with the $u v r C$ target gene, it serves in detecting any possible PCR inhibitors derived from the specimen DNA [25]. 


\section{Conclusions}

The $u v r C$ gene-based Taqman real-time PCR assay described in this study is much faster than conventional PCR and culture based identification of $M$. bovis. The Taqman assay results can be obtained within $2.5 \mathrm{~h}$ with greater sensitivity and specificity in identifying M. bovis DNA from clinical specimens. We have validated our $u v r C$ gene based Taqman real-time PCR assay to serve as a rapid and accurate test for the detection of $M$. bovis from a variety of clinical specimens.

\section{Acknowledgments}

We thank Ashlie McCarthy, Carlos Santisteban and Abhijit Gurjar of Quality Milk Production Services, Cornell University, Ithaca, New York for providing some of the reference isolates of Mycoplasma species that were used in our assay validation.

\section{Author Contributions}

Hemant Naikare contributed to the overall study design and analyses of the data, supervised the laboratory work and wrote the manuscript with Daniela Bruno. Daniela Bruno equally contributed towards study design, data compilation, and assisted in writing the manuscript. Debabrata Mahapatra and Alesia Reinisch extracted nucleic acids and performed P.C.R. experiments. Russell Raleigh performed isolation and identification of Mycoplasma sp. Debabrata Mahapatra, Alesia Reinisch and Russell Raleigh also assisted in preparing the manuscript. Robert Sprowls provided assistance with the study design and was involved in drafting the manuscript. All authors read and approved the final version of the manuscript.

\section{Conflicts of Interest}

The authors declare no conflict of interest.

\section{References}

1. Nicholas, R.A.; Ayling, R.D. Mycoplasma bovis: Disease, diagnosis and control. Res. Vet. Sci. 2003, 74, 105-112.

2. Goll, F., Jr. Identification of mycoplasmas isolated from domestic animals. In Mycoplasmosis in Animals: Laboratory Diagnosis; Whitford, H.W., Rosenbusch, R.F., Lauerman, L.H., Eds.; Iowa State University Press: Ames, IA, USA, 1994; pp. 15-27.

3. Rosenbusch, R.F. Biology and Taxonomy of Mycoplasmas. In Mycoplasmosis in Animals: Laboratory Diagnosis; Whitford, H.W., Rosenbusch, R.F., Lauerman, L.H., Eds.; Iowa State University Press: Ames, IA, USA, 1994; pp. 3-11.

4. Pfutzner, H.; Sachse, K. Mycoplasma bovis as an agent of mastitis, pneumonia, arthritis and genital disorders. Revue Sci. Tech. 1994, 15, 1477-1494.

5. Nicholas, R.A.J.; Baker, S.E. Recovery of Mycoplasmas from Animals. In Mycoplasma Protocols; Miles, R.J., Nicholas, R.A.J., Eds.; Humana Press: Totowa, NJ, USA, 1998; pp. 37-44.

6. Jasper, D.E. Bovine Mycoplasma mastitis. Adv. Vet. Sci. Comp. Med. 1981, 25, 121-159. 
7. Caswell, J.L.; Archambault, M. Mycoplasma bovis pneumonia in cattle. Anim. Health Res. Rev. 2007, 8, 161-186.

8. Kumar, A.; Verma, A.K.; Rahal, A. Mycoplasma bovis, A Multi Disease Producing Pathogen: An Overview. Asian J. Anim. Vet. Adv. 2011, 6, 537-546.

9. Wise, K.S.; Calcutt, M.J.; Foecking, M.F.; Röske, K.; Madupu, R.; Methé, B.A. Complete genome sequence of Mycoplasma bovis type strain PG45 (ATCC 25523). Infect. Immun. 2011, 79, 982-983.

10. Subramaniam, S.; Bergonier, D.; Poumarat, F.; Capaul, S.; Schlatter, Y.; Nicolet, J.; Frey, J. Species identification of Mycoplasma bovis and Mycoplasma agalactiae based on the uvrC genes by PCR. Mol. Cell. Probes 1998, 12, 161-169.

11. Bashiruddin, J.B.; Frey, J.; Königsson, M.H.; Johansson, K.E.; Hotzel, H.; Diller, R.; deSantis, P.; Botelho, A.; Ayling, R.D.; Nicholas, R.A.; et al. Evaluation of PCR systems for the identification and differentiation of Mycoplasma agalactiae and Mycoplasma bovis: A collaborative trial. Vet. J. 2005, 169, 268-275.

12. Clothier, K.A.; Jordan, D.M.; Thompson, C.J.; Kinyon, J.M.; Frana, T.S.; Strait, E.L. Mycoplasma bovis real-time polymerase chain reaction assay validation and diagnostic performance. J. Vet. Diagn. Invest. 2010, 22, 956-960.

13. Cai, H.Y.; Bell-Rogers, P.; Parker, L.; Prescott, J.F. Development of a real-time PCR for detection of Mycoplasma bovis in bovine milk and lung samples. J. Vet. Diagn. Invest. 2005, 17, 537-545.

14. McAuliffe, L.; Ellis, R.J.; Lawes, J.R.; Ayling, R.D.; Nicholas, R.A. 16S rDNA PCR and denaturing gradient gel electrophoresis; a single generic test for detecting and differentiating Mycoplasma species. J. Med. Microbiol. 2005, 54, 731-739.

15. Bai, Z.; Shi, L.; Hu, C.; Chen, X.; Qi, J.; Ba, X.; Peng, Q.; Chen, Y.; Chen, H.; Guo, A. Development of a loop-mediated isothermal amplification assay for sensitive and rapid detection of Mycoplasma bovis. Afr. J. Biotechnol. 2011, 10, 12333-12338.

16. Thomas, A.; Dizier, I.; Linden, A.; Mainil, J.; Frey, J.; Vilei, E.M. Conservation of the uvrC gene sequence in Mycoplasma bovis and its use in routine PCR diagnosis. Vet. J. 2004, 168, 100-102.

17. Marenda, M.S.; Sagne, E.; Poumarat, F.; Citti, C. Suppression subtractive hybridization as a basis to assess Mycoplasma agalactiae and Mycoplasma bovis genomic diversity and species-specific sequences. Microbiology 2005, 151, 475-489.

18. Lee, K.H.; Lee, J.W.; Wang, S.W.; Liu, L.Y.; Lee, M.F.; Chuang, S.T.; Shy, Y.M.; Chang, C.L.; Wu, M.C.; Chi, C.H. Development of a novel biochip for rapid multiplex detection of seven mastitis causing pathogens in bovine milk samples. J. Vet. Diagn. Investig. 2008, 20, 463-471.

19. Gonzalez, Y.R.C.; Baccunana, C.R.; Bolske, G.; Mattsson, J.G.; Molina, C.F.; Johansson, K.E. In vitro amplification of the $16 \mathrm{~S}$ rRNA genes from Mycoplasma bovis and Mycoplasma agalactiae by PCR. Vet. Microbiol. 1995, 47, 183-190.

20. Moser, M.J.; Christensen, D.R.; Norwood, D.; Prudent, J.R. Multiplexed detection of anthrax-related toxin genes. J. Mol. Diagn. 2006, 8, 89-96.

21. González, R.N.; Sears, P.M.; Wilson, D.J. Diagnosis of Intramammary Infections Due to Mycoplasma bovis in Dairy Cattle. In Proceedings of the 3rd IDF International Mastitis Seminar, 1995; Volume S-2, pp. 23-27. 
22. Bell, C.J.; Blackurn, P.; Elliott, M.; Patterson, T.I.; Ellison, S.; Lahuerta-Marin, A.; Ball, H.J. Investigation of polymerase chain reaction assays to improve detection of bacterial involvement in bovine respiratory disease. J. Vet. Diagn. Investig. 2014, 26, 631-634.

23. Castillo-Alcala, F.; Bateman, K.G.; Cai, H.Y.; Schott, C.R.; Parker, L.; Clark, M.E.; McRaild, P.; McDowall, R.M.; Foster, R.A.; Archambault, M.; et al. Prevalence and genotype of Mycoplasma bovis in beef cattle after arrival at a feedlot. Am. J. Vet. Res. 2012, 73, 1932-1943.

24. Justice-Allen, A.; Trujillo, J.; Goodell, G.; Wilson, D. Detection of multiple Mycoplasma species in bulk tank milk samples using real-time PCR and conventional culture and comparison of test sensitivities. J. Dairy Sci. 2011, 94, 3411-3419.

25. Hoorfar, J.; Malorny, B.; Abdulmawjood, A.; Cook, N.; Wagner, M.; Fach, P. Practical considerations in design of internal amplification controls for diagnostic PCR assays. J. Clin. Microbiol. 2004, 42, $1863-1868$.

(C) 2015 by the authors; licensee MDPI, Basel, Switzerland. This article is an open access article distributed under the terms and conditions of the Creative Commons Attribution license (http://creativecommons.org/licenses/by/4.0/). 